\title{
The Effect of Microstructure on the Dynamic Equi-Biaxial Fatigue Behaviour of Magnetorheological Elastomers
}

\author{
Yanfen Zhou \\ Technological University Dublin, yanfen.zhou@mydit.ie \\ Stephen Jerrams \\ Technological University of Dublin, stephen.jerrams@tudublin.ie \\ Tony Betts \\ Technological University of Dublin, anthony.betts@tudublin.ie
}

See next page for additional authors

Follow this and additional works at: https://arrow.tudublin.ie/cercon

Part of the Polymer and Organic Materials Commons

\section{Recommended Citation}

Zhou, Y., Jerrams, S., Betts, A. \& Chen, L. (2013) The Effect of Microstructure on the Dynamic Equi-Biaxial Fatigue Behaviour of Magnetorheological Elastomers, 8th European Conference on Constitutive Models for Rubbers (ECCMR VIII), San Sebastian, Spain, 25 -28 June, 2013.

This Conference Paper is brought to you for free and open access by the Centre for Elastomer Research at ARROW@TU Dublin. It has been accepted for inclusion in Conference Papers by an authorized administrator of ARROW@TU Dublin. For more information, please contact arrow.admin@tudublin.ie, aisling.coyne@tudublin.ie,gerard.connolly@tudublin.ie. Funder: Irish Research Council

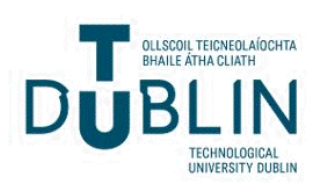




\section{Authors}

Yanfen Zhou, Stephen Jerrams, Tony Betts, and Lin Chen 


\title{
The effect of microstructure on the dynamic equi-biaxial fatigue behaviour of magnetorheological elastomers
}

\author{
Y.F. Zhou \& S. Jerrams \\ Center for Elastomer Research, Focas Research Institute, Dublin Institute of Technology, Dublin 8, Ireland
}

A. Betts

Applied Electrochemistry Group, Focas Research Institute, Dublin Institute of Technology, Dublin 8, Ireland

L. Chen

Beijing Aeronautical Science and Technology Research Institute, Future Science and Technology Park, Changping District, Beijing, 102211, China

\begin{abstract}
Dynamic equi-biaxial fatigue behaviour of isotropic and anisotropic magnetorheological elastomers (MREs) based on a silicone rubber matrix was investigated using the bubble inflation method. Constant engineering stress amplitude was used as the control mode and samples were fatigued over different stress ranges between $0.75 \mathrm{MPa}$ and $1.4 \mathrm{MPa}$. S-N (Wöhler) curves showing plots of stress amplitude $\left(\sigma_{\mathrm{a}}\right)$ versus cycles to failure $(\mathrm{N})$ are presented. Stress-strain behaviour throughout the fatigue process is described. Elastic modulus $\left(\mathrm{E}^{*}\right)$ was studied for the specific cycles measured. It was found that anisotropic MREs exhibited greater fatigue resistance than isotropic MREs for a given magnetic particle content. Stress softening and hysteresis continued throughout the tests though they were most pronounced in the first dozen cycles at the lower stress amplitudes. A limiting value of $\mathrm{E}^{*}$, below which fatigue failure is likely to take place was observed in both isotropic and anisotropic MREs, although the initial modulus was higher in anisotropic MREs.
\end{abstract}

\section{INTRODUCTION}

Magnetorheological elastomers (MREs) belong to a family of so-called smart materials which consist of micron sized magnetically permeable particles suspended in a non-magnetic medium (Boczkowska et al. 2007). Upon application of a magnetic field, the rheological properties of these materials are rapidly and reversibly altered (Lokander \& Stenberg 2004). Various elastomers such as silicone rubber (Lockette et al. 2008, Farshad \& Benine 2004), natural rubber (Chen et al. 2007) and polyurethane (Boczkowska et al. 2009) have been used as the rubber matrix to produce MREs with different properties. MREs can be fabricated either in the absence of, or in the presence of a magnetic field during the curing process. The former technique results in isotropic or homogenous MREs (Gong et al. 2005, Lokander \& Stenberg 2003) while the latter results in anisotropic MREs with particles aligned into chain-like and columnar structures parallel to the direction of the applied field (Zhang et al. 2010). These aligned composites display strong anisotropy in their mechanical, electrical, magnetic and thermal properties.

MREs hold the promise of stiffness tunable devices (Watson 1997, Stewart et al. 1998) and adaptive tuned vibration absorbers (Gregory 2005, Deng et al. 2006, Deng \& Gong 2008). For engineering applications, the high dynamic loading experienced by machine parts necessitates the understanding of fatigue properties in MREs, particularly through multi-axial fatigue testing which can provide representative fatigue behaviour and life prediction for MREs.

In this text, the fabrication of isotropic and anisotropic MREs and their equi-biaxial fatigue behaviours using the bubble inflation system (see Figure 1 ) is described. The aim of this research was to determine the effect of microstructure on the fatigue behaviour of MREs subjected to equi-biaxial loading. To this end, fatigue life, stress-strain behaviour during fatigue and elastic modulus were compared for isotropic and anisotropic MRE samples.

\section{EXPERIMENT}

\subsection{Materials}

A two component, room temperature vulcanized (RTV) silicone rubber comprising the base elastomer and a catalyst, procured from Axson Technology, UK, was used as the matrix material. Soft carbonyl iron (CS grade, $\mathrm{d} 50=6.0-7.0 \mu \mathrm{m}$, density $=$ $7.86 \mathrm{~g} / \mathrm{cm}^{3}$, supplied by BASF) was selected as the magnetic particle to fabricate the MREs because it possesses excellent soft magnetic properties and high saturation magnetization. 


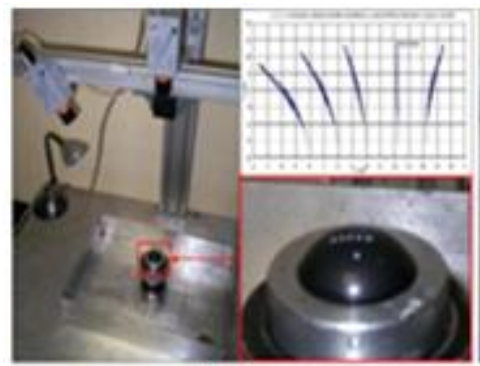

(a)

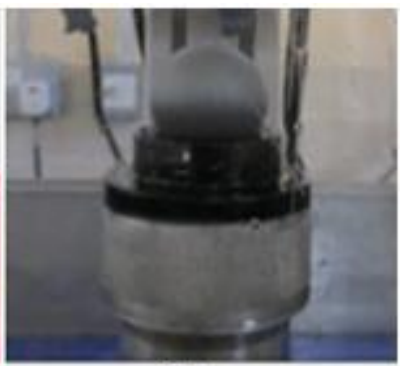

(b)
Figure 1. The equal-biaxial bubble inflation test system (a), a graph depicting the tracking of the displacement of dots at the pole of the bubble; (b) an inflated MRE sample

\subsection{Fabrication of MREs}

Both isotropic and anisotropic MREs with a carbonyl iron content of $20 \mathrm{vol} \%$ were produced. Firstly, silicone rubber was mixed with a catalyst at a 10:1 ratio. Then the carbonyl iron particles were incorporated into the mixture and mechanically stirred to distribute the particles evenly in the elastomer matrix. The whole mixture was degassed in a vacuum to remove entrapped air bubbles and then poured into a mould. After further degassing in the mould, the compound was kept at room temperature for $48 \mathrm{~h}$ to allow solidification. For anisotropic MREs, the compound was cured in the presence of a magnetic field using a Halbach Array after degassing. The Halbach Array can provide a mean magnetic flux of $400 \mathrm{mT} \pm 5 \%$ over the $50 \mathrm{~mm}$ nominal diameters of the test samples. The thickness of the MRE samples fabricated was $1 \mathrm{~mm}$.

\subsection{Microscopy observation}

The microstructures of the isotropic and anisotropic MREs were observed using a Scanning Electron Microscope (SEM, Zeiss Supra). Samples were coated with a fine layer of gold to make them conductive and SEM images were taken with an accelerating voltage of $5 \mathrm{KV}$.

\subsection{Bubble inflation testing}

The test samples were retained in the hydraulic bubble inflation system's inflation orifice for cycling. Initially, quasi-static tests were carried out to determine a value of failure stress and stress-strain relationship for initial loading. This allowed the equibiaxial dynamic test parameters to be set. Thereafter, fatigue tests were conducted over a range of stress amplitudes with a minimum stress of zero. Typically, pressure was applied to test samples causing them to inflate. The vision system, utilizing two charge coupled device (CCD) cameras, recorded the movement of specific points at the pole on the sur-

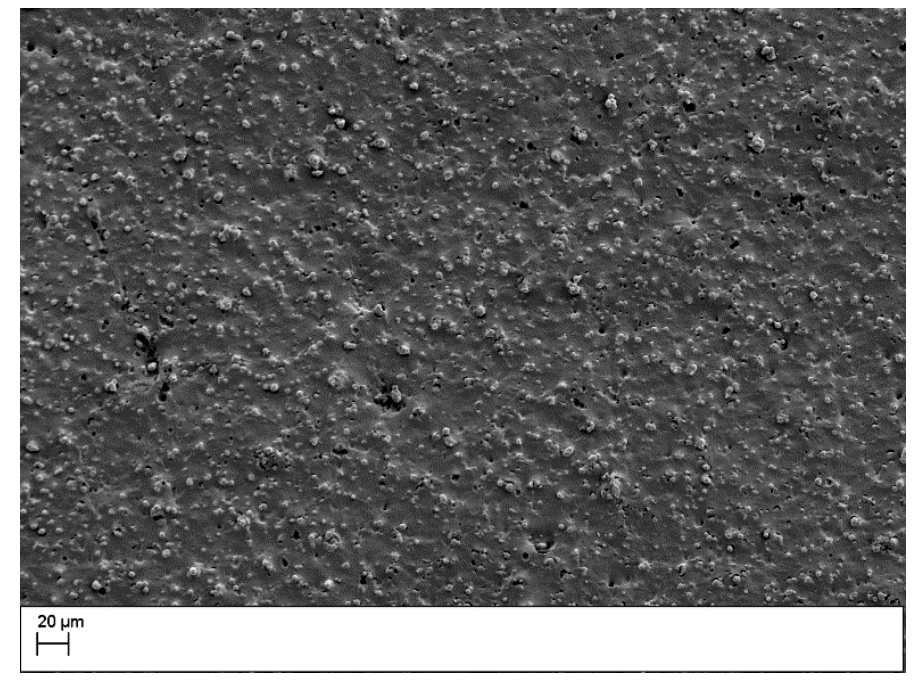

Figure 2. SEM image of isotropic MREs

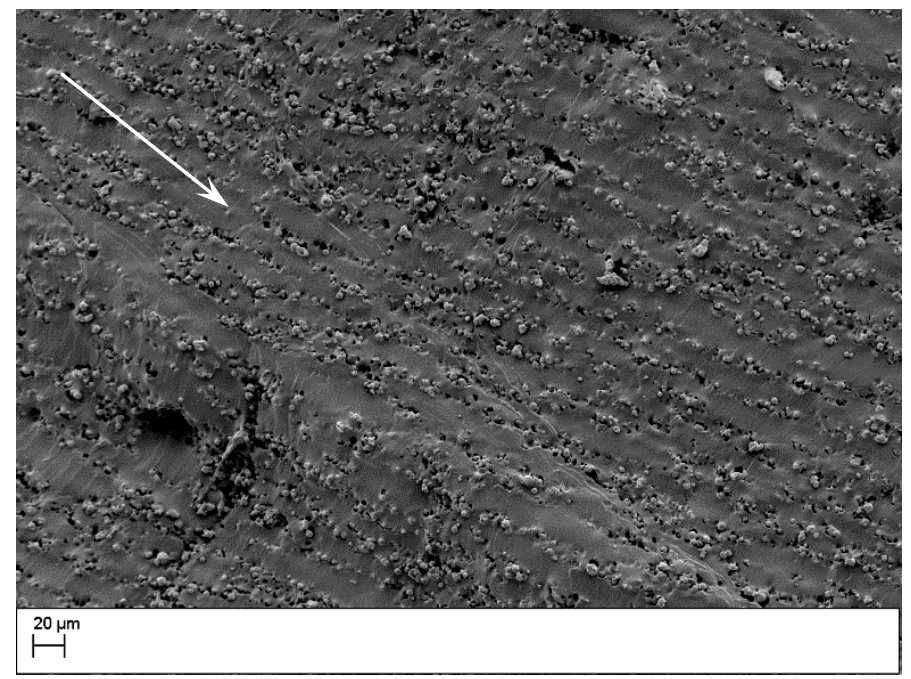

Figure 3. SEM image of anisotropic MREs, arrow shows the direction of the magnetic field

face of a sample during inflation and deflation. Stress values were simultaneously calculated from the applied pressure and bubble geometry, while strain values were calculated from the change in surface distance between specific points at the bubble pole on the bubble surface, using three dimensional position coordinates obtained from the vision system output. Throughout these tests, the dynamic test facility continually recorded dimensional changes in the bubble and corrected pressure limits to maintain constant engineering stress $\left(\sigma_{\text {Eng }}\right)$. The dynamic test facility was integrated with a system control programme to count the accumulated cycles. The theory for obtaining stress-strain relations is described elsewhere (Jerrams et al. 2012).Test samples were not cycled in the presence of a magnetic field in the tests described here. 


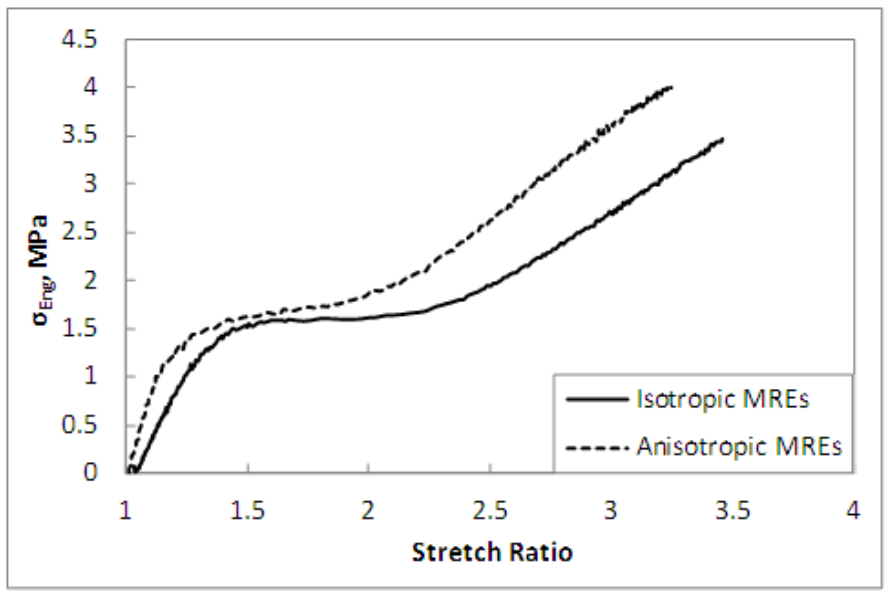

Figure 4. Stress-strain relations from quasi-static test

\section{RESULTS AND DISCUSSION}

\subsection{Microstructure of isotropic and anisotropic MREs}

The SEM images for isotropic and anisotropic MREs are shown in Figure 2 and Figure 3 respectively. As can be seen from these figures, carbonyl iron particles were distributed randomly in isotropic MREs but they formed chain-like structures in the direction of the magnetic field in anisotropic MREs.

\subsection{Quasi-static testing}

Quasi-static tests to failure were carried out on both isotropic and anisotropic MREs and the average strength at failure was $3.5 \mathrm{MPa}$ and $4.1 \mathrm{MPa}$ respectively. These values were used to set stress amplitudes in the subsequent fatigue tests. Figure 4 shows the stress-strain curves from a quasi-static test for isotropic and anisotropic MREs. As can be observed, the stress-strain curve of an equi-biaxial test results in a similar ' $S$ ' shaped configuration to that seen in typical uniaxial tensile tests on rubber compounds. Unsurprisingly, the stiffer anisotropic MREs exhibited lower extensibility.

\subsection{S-N curves}

Equi-biaxial fatigue tests were carried out at four different stress amplitudes ranging between $0.75 \mathrm{MPa}$ and $1.4 \mathrm{MPa}$ with a minimum stress of zero under engineering stress control. A minimum of three tests were carried out for each stress amplitude and subsequently, standard S-N curves were produced to depict fatigue lives for isotropic and anisotropic MREs, as shown in Figure 5.

When fatigue lives were compared at the same stress amplitude, it was found that anisotropic MREs exhibited greater fatigue resistance than isotropic MREs.

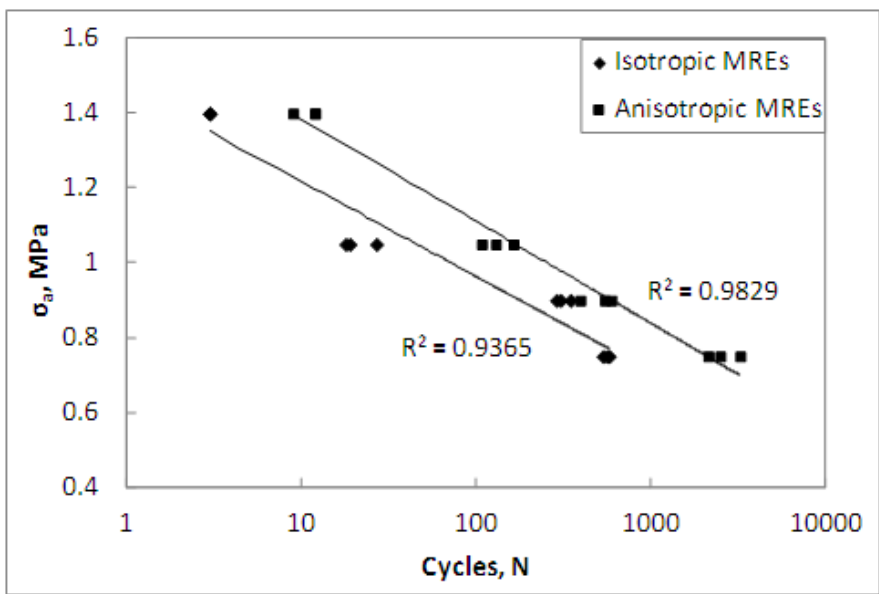

Figure 5. S-N curves for isotropic and anisotropic MREs

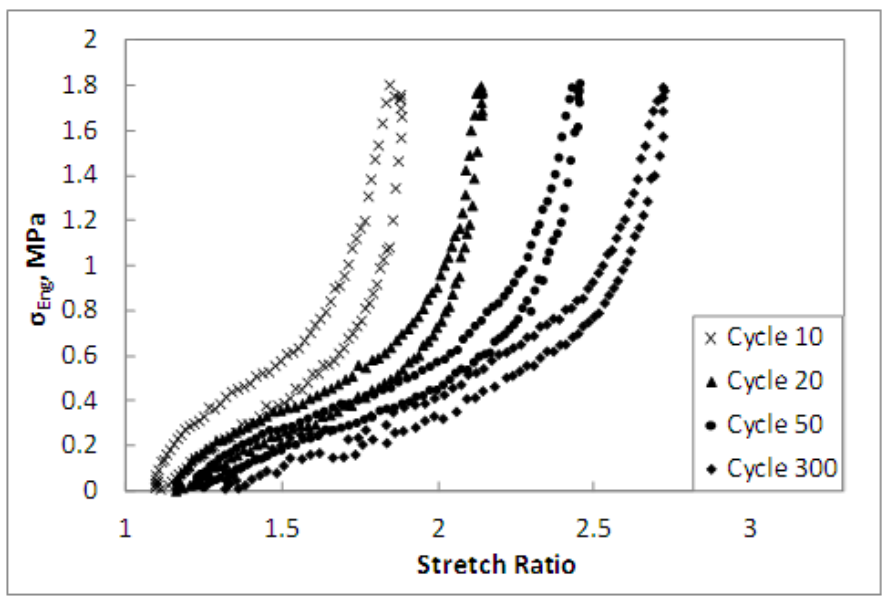

Figure 6. Stress-strain behaviour for isotropic MREs for selected cycles, $\sigma_{\mathrm{a}}=0.9 \mathrm{MPa}$, (failure occurred at 305 cycles)

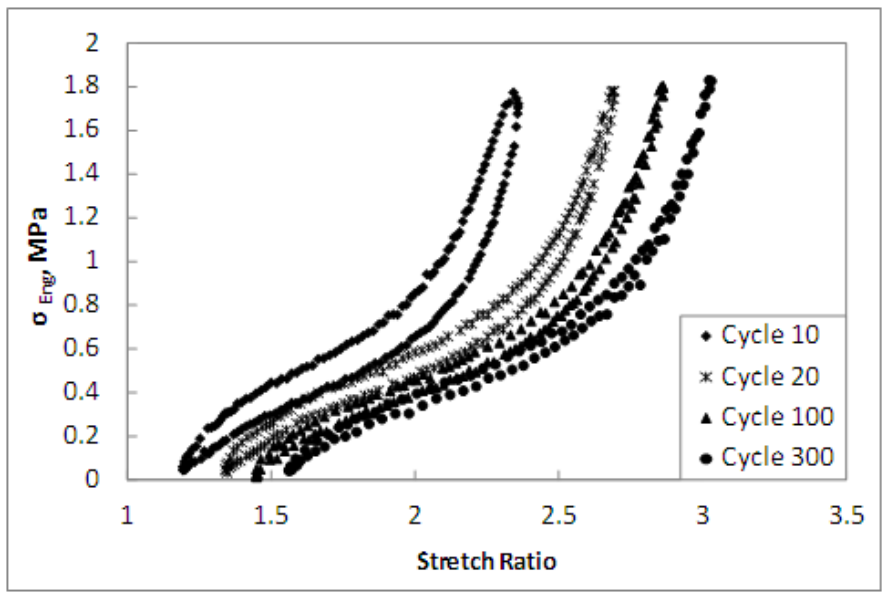

Figure 7. Stress-strain behaviour for anisotropic MREs for selected cycles, $\sigma_{\mathrm{a}}=0.9 \mathrm{MPa}$, (failure occurred at 395 cycles)

This can be attributed to the formation of carbonyl iron chains in anisotropic MRE samples during the curing process.

\subsection{Stress-strain behaviour}

The stress-strain behaviour of isotropic and anisotropic MREs at a stress amplitude of $0.9 \mathrm{MPa}$ is de- 
picted in Figure 6 and Figure 7 respectively. The plots clearly indicate that the algorithm employed to maintain constant engineering stress limits as the test-piece material softened, kept the stress range within acceptable levels. It can be observed that stress softening and hysteresis continued throughout the test and was particularly pronounced in the first dozen cycles for both isotropic and anisotropic MREs. Furthermore, the dynamic cyclic loading induced an increase in permanent set as each test progressed but this increase was much greater in isotropic MREs than in anisotropic MREs.

\subsection{Elastic modulus}

It is usual for the modulus of filled rubber to decrease significantly in the first few cycles of a physical test as a result of stress softening (Abraham et al. 2005). Previous research into conventional elastomers (ethylene propylene diene monomer, EPDM and styrene-butadiene rubber, SBR) by Abraham (Abraham et al. 2006 \& 2001) and Alshuth et al (Alshuth et al. 2002) suggested that specific elastomers when subjected to uniaxial cyclic loading exhibited a limiting value of $\mathrm{E}^{*}$ and that this value could be used effectively to design against fatigue failure in rubber components. The concept of a limiting value of $\mathrm{E}^{*}$ was supported by Jerrams et al (Jerrams et al. 2012, Jerrams et al. 2008) and Hanley et al (Hanley et al. 2008, Hanley 2008) for EPDM samples, both swollen and unswollen, subjected to equi-biaxial stress cycles.

The tests on silicone based MREs described here further strengthen the conclusion that irrespective of stress amplitude and loading method, fatigue failure occurs (within limits) at a specific value of $\mathrm{E}^{*}$, as shown in Figure 8 and Figure 9. For isotropic MREs, failure took place at $\mathrm{E}^{*}$ values between $1.16 \mathrm{MPa}$ and $1.29 \mathrm{MPa}(1.228 \mathrm{MPa} \pm 5.38 \%)$ while for anisotropic MREs, failure occurred at $\mathrm{E}^{*}$ values between $1.16 \mathrm{MPa}$ and $1.41 \mathrm{MPa}(1.295 \mathrm{MPa} \pm$ $13.38 \%$ ).

When the values of $\mathrm{E}^{*}$ are compared for isotropic and anisotropic MREs at the same stress amplitude, it was noted that anisotropic MREs had a higher initial modulus. But the rate of decrease was more rapid in anisotropic specimens, as shown in Figure 10. The high initial $\mathrm{E}^{*}$ in anisotropic MREs is thought to be due to the formation of carbonyl iron chains. However, once these chains were broken, the material experienced a rapid drop in modulus until failure.

\section{CONCLUSIONS}

The equi-biaxial fatigue behaviour of isotropic and anisotropic MREs was investigated by using the dy-

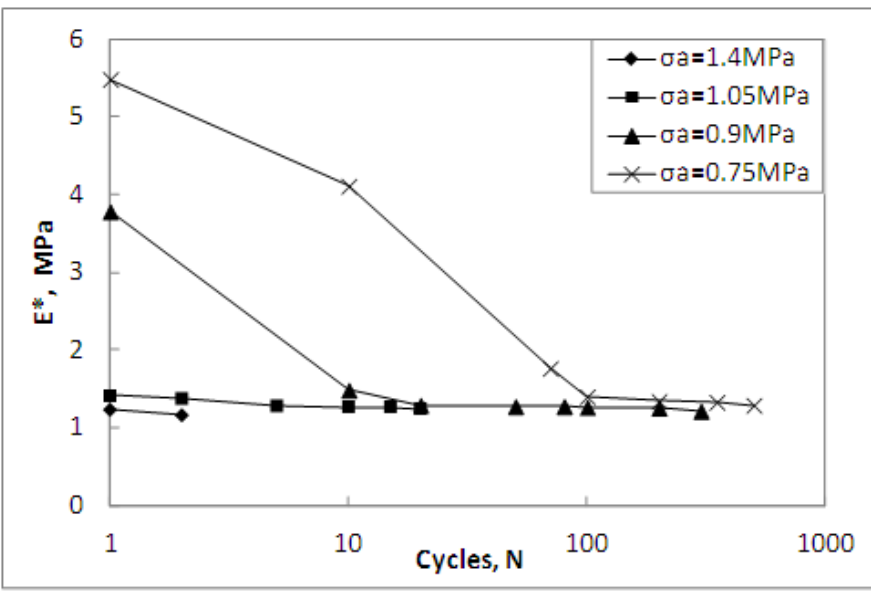

Figure $8 . \mathrm{E}^{*}$ versus $\log (\mathrm{N})$ at different stress amplitudes for isotropic MREs

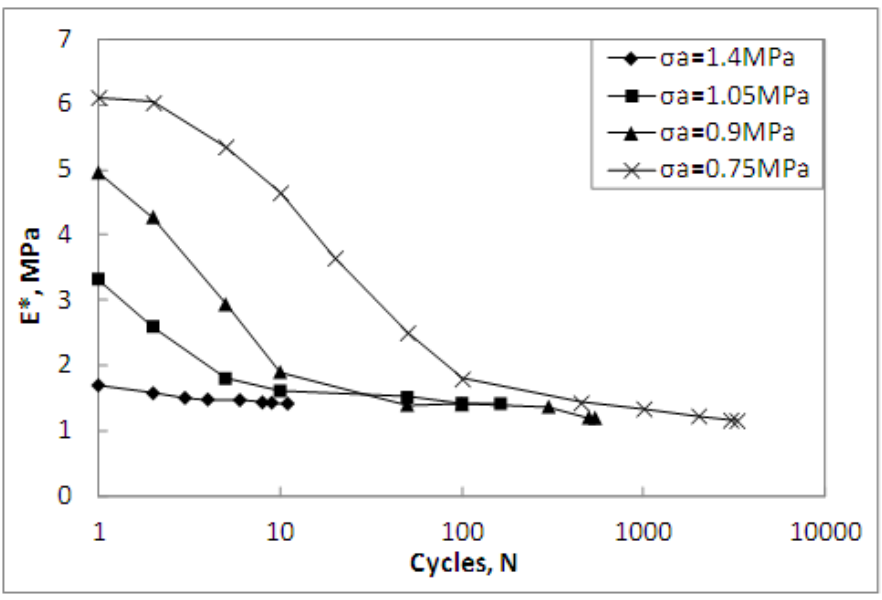

Figure 9. $\mathrm{E}^{*}$ versus $\log (\mathrm{N})$ at different stress amplitudes for anisotropic MREs

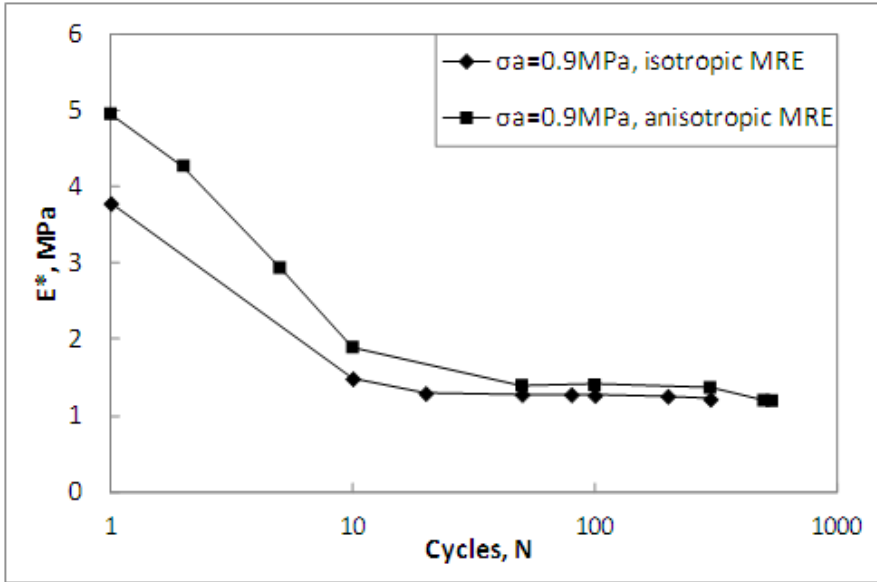

Figure 10. $\mathrm{E}^{*}$ versus $\log (\mathrm{N})$ for isotropic and anisotropic MREs at $\sigma_{\mathrm{a}}=0.9 \mathrm{MPa}$

namic bubble inflation method. The following conclusions can be drawn:

- Anisotropic MREs have a higher failure strength than isotropic MREs due to the formation of carbonyl iron chains during the curing process.

- Anisotropic MREs exhibit greater fatigue resistance than isotropic MREs for a given magnetic particle content. 
- For both isotropic and anisotropic MREs, stress softening and hysteresis continued throughout fatigue testing but they were most pronounced in the first dozen cycles and then became insignificant at lower stress amplitudes. However, the permanent set induced by the dynamic cyclic loading was higher in isotropic MREs than in anisotropic MREs.

- During the equi-biaxial fatigue tests on MREs, the complex modulus $\left(\mathrm{E}^{*}\right)$ decreased throughout the entire test and attained a limiting value of approximately $1.228 \mathrm{MPa} \pm 5.38 \%$ for isotropic MREs and $1.295 \mathrm{MPa} \pm 13.38 \%$ for anisotropic MREs. Structured MREs had a higher initial modulus but the rate of decrease in modulus was more rapid than that in isotropic MREs.

Future work will focus on design of interfacial layers with controlled and consistent properties between magnetic particles and the elastomeric matrices. It will be determined if the introduction of interfacial layers can improve fatigue resistance in MREs.

\section{ACKNOWLEDGEMENTS}

This work is made possible by funding from the Irish Research Council (Science, Engineering and Technology, IRCSET).

\section{REFERENCES}

[1] Boczkowska, A., Awietjan, S.F. \& Wroblewski R. 2007. Microstructure-property relationships of urethane magnetorheological elastomers, Smart Materials and Structures, $16,1924-1930$

[2] Lokander, M., Reitberger, T., Stenberg, B. 2004. Oxidation of natural rubber-based magnetorheological elastomers, $P o$ lymer Degradation and Stability, 86, 467-471

[3] Von Lockette, P.R., Lofland, S.E, Koo, J.H., Kadlowec, J., Dermond, M. 2008. Dynamic characterization of bimodal particle mixtures in silicone rubber magnetorheological materials, Polymer Testing, 27, 931-935

[4] Farshad, M., Benine, A. 2004. Magnetoactive elastomer composites, Polymer Testing, 23, 347-353

[5] Chen, L. Gong, X.L., Jiang, W.Q., Yao, J.J., Deng, H.X., Li, W.H. 2007. Investigation on magnetorheological elastomers based on natural rubber, Journal of Materials Science, 42, 5483-5489

[6] Boczkowska, A., Awietjan, S. F., Wejrzanowski, T., Kurzydlowski, K.J. 2009. Image analysis of the microstructure of magnetorheological elastomers, Journal of Materials Science, 44, 3135-3140

[7] Gong, X.L., Zhang, X.Z., Zhang, P.Q. 2005. Fabrication and characterization of isotropic magnetorheological elastomers, Polymer Testing, 24, 669-676

[8] Lokander, M., Stenberg, B. 2003. Improving the magnetorheological effect in isotropic magnetorheological rubber materials, Polymer Testing, 22, 677-680

[9] Zhang, W., Gong, X.L., Jiang, W.Q., Fan, Y.C. 2010. Investigation of the durability of anisotropic magnetorheolog- ical elastomers based on mixed rubber, Smart Materials and Structures, 19, 085008 (10pp)

[10] Watson, J. R. 1997. US Patent, No: 5,609,353

[11] Stewart, W.M., Ginder J.M., Elie, L.D., Nichols, M.E. 1998. US Patent, No: 5,816,587

[12] Hitchcock, G.H., Gordaninejad, F., Fuchs, A. 2005. US Patent, No: 2005/0011710 A1

[13] Deng, H.X., Gong, X.L., Wang, L.H. 2006. Development of an adaptive tuned vibration absorber with magnetorheological elastomer, Smart Materials and Structures, 15 N111-N116

[14] Deng, H.X., Gong, X.L. 2008. Application of magnetorheological elastomer to vibration absorber, Nonlinear Science and Numerical Simulation, 13, 1938-1947

[15] Jerrams, S., Murphy, N., Hanley, J. 2012. The significance of equi-biaxial bubble inflation in determining elastomeric fatigue properties, Advanced Elastomers, Technology, Properties and Applications, Rijeka, Intech, 379-381

[16] Abraham, F., Alshuth, T. and Jerrams, S. 2005. The effect of minimum stress and stress amplitude on the fatigue life of non strain crystallising elastomers, Journal of Materials and Design, 26, 239-245

[17] Abraham, F., Alshuth, T., Jerrams, S. 2006. Parameter dependence of the fatigue life of elastomers, Elastomers and Components: Service Life Prediction - Progress and Challenges, London, Woodhead

[18] Abraham, F., Alshuth, T., Jerrams, S. 2001. Dependence on mean stress and stress amplitude of fatigue life of EPDM elastomers, Institute of Materials, 30, 9, 421-425

[19] Alshuth, T., Abraham, F., Jerrams, S. 2002. Parameter dependence and prediction of fatigue properties of elastomer products, Rubber Chemistry and Technology, 75, 4, 635-642

[20] Jerrams, S., Murphy, N., Hanley, J. 2012. The significance of equi-biaxial bubble inflation in determining elastomeric fatigue properties, Advanced Elastomers, Technology, Properties and Applications, Rijeka, Intech, 382-386

[21] Jerrams, S., Hanley, J., Murphy, N., Ali. H. 2008. Equibiaxial fatigue of elastomers -The effect of oil swelling in specimen fatigue life, Rubber Chemistry and Technology, $81,4,638-649$

[22] Hanley, J., Jerrams, S., Murphy, N. 2008. The effect of oil swelling on the fatigue life of EPDM samples subjected to equi-biaxial cyclic loading. Time Dependent Behaviour of Rubber Conference \& The Rubber Foundation Lecture, London

[23] Hanley, J. 2008. PhD dissertation. Swelling effects in dynamic equi-biaxial testing of EPDM elastomers by the bubble inflation method, Dublin Institute of Technology (DIT) 